\title{
Cérebros, Mapas e o Novo Território da Psicologia
}

\author{
Anne Beaulieu \\ Royal Netherlands Academy of Arts and Sciences
}

Theory \& Psychology Copyright (C 2003 Sage Publications. Vol. 13(4): 561-568

[0959-3543(200308)13:4;561-568;034694]

\begin{abstract}
Resumo
$\mathrm{Na}$ última década, tem-se visto o crescimento do interesse no uso dos métodos de imageamento funcional do cérebro em pesquisas. A variedade das condições e comportamentos estudados usando esses métodos também tem se expandido. Esses desenvolvimentos têm alterado o perfil dos subcampos da psicologia e da neurociência. Enquanto esses acontecimentos são criticados como movimentos reducionistas, eu argumento que eles podem ser melhor caracterizados como processos produtivos. Esse tipo de caracterização torna visível a expansão e reorganização do objeto de estudo e de domínios de investigação; ele destaca novas relações com outras disciplinas e instituições e problematiza o subseqüente incremento na visibilidade social. Uma abordagem reflexiva para o mapeamento das práticas é proposto para ajudar as pesquisas de imageamento funcional no direcionamento das questões de segregação e responsabilidade metodológicas.
\end{abstract}

Palavras-chave: Mapeamento Cerebral, História do Imageamento Funcional, Neuroética, Reducionismo, Reflexividade.

\begin{abstract}
The past decade has seen growing interest in the use of functional brain imaging methods in research. The range of conditions and behaviours studied using these methods has also been expanding. These developments have changed the profile of subfields in both psychology and neuroscience. While these events have been critiqued as reductionist moves, I argue that they can better be characterized as productive processes. Such a characterization makes visible the expansion and reorganization of the object of study and of domains of investigation; it highlights new relations with other disciplines and institutions, and it problematizes the subsequent increased social visibility. A reflexive approach to mapping practices is proposed to help functional imaging research address issues of methodological isolation and accountability.
\end{abstract}


Key Words: Brain Mapping, History of Functional Imaging, Neuroethics, Reductionism, Reflexivity

\section{Tudo no Cérebro}

$\mathrm{O}$ argumento de que 'tudo está no cérebro' dificilmente suscita dúvidas. Quase todos os meses, uma nova área para tal processo ou uma rede para aquele comportamento é encontrado e amplamente divulgado. De fato, ao longo da Década do Cérebro, a ideia de uma base biológica para a mente tornou-se enraizada, tanto no discurso popular quanto no científico. Algumas declarações sobre as bases biológicas de certos traços de personalidade ainda podem ocasionalmente surpreender e chocar. Um artigo recente afirma ter encontrado os substratos biológicos para atitudes raciais (Phelps et al., 2000). Como poderiam atitudes culturais tão complexas estar relacionadas aos tecidos do cérebro e a circulação sanguínea? Um grupo de sujeitos foi escaneado enquanto observavam rostos negros e brancos, e a atividade foi mensurada em suas amígdalas (uma estrutura envolvida na aprendizagem emocional e no medo). O nível de atividade correspondia aos resultados dos sujeitos nos testes de 'avaliação racial' aplicados antes dos scans. Esse estudo foi publicado em um dos principais periódicos científicos americanos. Não se seguiu nenhum protesto. Exatamente como medir esse traço pode ser debatido, mas aquele medo de que o Outro está conectado em nossos cérebros é uma ideia que pode ser levada em consideração. É também uma ideia que parece não apenas carregar a agenda de um novo estilo de pesquisa psicológica, mas também de abraçar o compromisso de aprimoramento nas relações sociais. Se os mecanismos biológicos do medo podem ser identificados, eles eventualmente podem também ser (biologicamente, farmacologicamente) modulados.

O que não quer dizer que a metodologia do mapeamento cerebral não vem sendo debatida, tanto dentro quanto fora da comunidade de pesquisa. Figuras como Jerry Fodor e Tom Wolfe escreveram sobre as fraquezas desta abordagem. Wolfe (1997) preocupa-se com a queda de noções como cultura, self e alma, como um resultado dos cientistas examinando dentro de nossos cérebros, tornando-os transparentes 
através das tecnologias de imageamento. Fodor (1999) insiste na importância de fazer questões sobre a mente, para além de observar áreas específicas do cérebro iluminando-se em relação a uma determinada tarefa. Certamente, uma linha de argumento comumente ouvida quando se discute mapeamento cerebral consiste em denunciar o reducionismo potencial dos mapas cerebrais e apontar as limitações dos scans. Esse tipo de crítica não deixa de ser interessante, mas pode perder importantes aspectos sociais e científicos desta nova tendência. Uma crítica sobre esses mapas que visibilize suas complexidades e o modo como são produtivos (não apenas redutivos) pode proporcionar um melhor trabalho de contextualização desta nova corrente de pesquisa.

\section{A Função dos Mapas}

O que é isso que estes mapas fazem* , e por que isso é valorizado? A que propósito estes mapas do cérebro estão servindo? A resposta se baseia em um princípio simples e detalhes técnicos

\footnotetext{
${ }^{*}$ N.T. Aqui a autora faz um jogo de palavras com a língua inglesa: "What is it that these maps do do"(...).
}

complexos. Em uma frase: mapas ligam a vida da mente e o espaço do cérebro.

O desenvolvimento do mapeamento do cérebro tem marcado uma importante mudança na prática de experimentos em certas áreas da psicologia e da neurociência. Pela utilização de experimentos de escaneamento, fenômenos que estavam sendo estudados utilizando medidas comportamentais, vieram a ser estudados utilizando base cerebral, e, mais especificamente, medidas anatômicas. Em vez de focar nos processos da mente no tempo, o mapeamento cerebral redireciona a atenção para padrões no espaço do cérebro (Beaulieu, 2002). Essas mudanças no foco dos experimentos são detalhadas em Images of Mind, de Posner e Raichle (1997), dois pioneiros do método no final de 1980. Muitas das objeções sobre essa abordagem são formuladas em resposta a uma edição de Behavioral and Brain Sciences, na qual um resumo desse livro foi apresentado1. Essas localizações têm crescido em sofisticação ao longo da última década. Um crescimento complexo do conjunto de características da mente pode ser mapeado no cérebro. As experiências de vida, o impacto do ambiente e da aprendizagem, tem sido 
todos estudados em experimentos de mapeamento. Tem-se produzido mapas distinguindo como a linguagem é localizada em bilingues precoces e tardios. A memória espacial superior dos motoristas de táxi de Londres, os quais precisam aprender a memorizar as principais ruas da cidade para serem certificados, também tem sido mapeada como biologicamente diferente. Além de modificar as formas de trabalho de muitos psicólogos e neurocientistas, os mapas têm estado no centro de novas formas de argumentos sobre o natural e o aprendido. O mapeamento, é importante ressaltar, não ignora aspectos sociais e ambientais; ao contrário, ele recoloca estes aspectos em termos biológicos. $\mathrm{O}$ experimento sobre racismo descrito no início deste artigo é um claro exemplo de como até mesmo um conceito firmado em determinantes culturais como o racismo pode ser traduzido como uma reação no cérebro. Estes mapas ligam fatores sociais, psicológicos e ambientais à estrutura biológica do cérebro.

Pode-se dizer que o mapeamento reconfigura o debate natural/aprendido. Não é só o natural que conta; o aprendido também conta, mas apenas quando traduzido em ativação mensurável no cérebro. A biologização da mente no mapeamento cerebral leva o social ou o ambiental bastante a sério. Atribui-se a eles uma característica do mapa. Na popular revista Newsweek, o destino da carência de orfãos romenos foi largamente comparado ao de crianças normais através de dois PET scans, com as imagens sustentando para o impacto de negligência emocional como mensurado nos cérebros dos órfãos (Begley, 1997). Neste caso, a falta de educação foi apresentada como uma característica biológica.

Mais recentemente, os mapas cerebrais têm cada vez mais configurado o modo como a questão natural/aprendido está sendo colocada. Um estudo de cérebros gêmeos (Thompson et al., 2001) relacionou escaneamento cerebral com variação genética. Esse estudo também correlacionou estrutura cortical e resultados de teste de QI em relação à influência genética. $O$ que está acontecendo nesse exemplo não é a recusa em dar importância aos aspectos não biológicos das funções psicológicas, mas, ao contrário, uma complexa tradução dos fenômenos em mensurações do cérebro. Medindo os volumes das partes do cérebro e correlacionando-os aos graus de similaridade genética (através da bem 
conhecida estratégia de comparar gêmeos monozigóticos e gêmeos fraternos), as variações em volumes podem ser atribuídas a fatores genéticos ou ambientais. Esse estudo específico ainda sugeriu um possível mecanismo para explicar fatores hereditários em escores de QI: volumes de matéria cinza foram fortemente determinados geneticamente e puderam assim ser relacionados aos resultados obtidos pelos sujeitos.

Diferenças nas medidas de inteligência, diferenças nos graus de relacionamentos e diferenças no ambiente e experiência puderam ser todos comparados nesse estudo, porque eles foram traduzidos em caracteres de voxels, as unidades digitais que delineiam os escaneamentos do cérebro e servem para calcular volumes e níveis de atividade metabólica. Acusar o mapeamento cerebral de reducionismo é perder os caminhos pelos quais sua força redefine conceitos como comportamento, aprendido, cultura e ambiente. O papel relacional do mapa é, portanto, ligar contexto, mente e cérebro. Este é um dos modos pelo qual o impacto dos mapas é mais bem analisado como produtor de novas relações, em vez de condená-lo como reducionista.

\section{O Espaço do Corpo}

O foco do mapeamento cerebral no espaço e anatomia tem consequências ulteriores para o futuro da psicologia e neurociência. $\mathrm{O}$ alcance do mapeamento se extende às noções de self, no sentido de seu potencial e de sua biografia. Assim como essas noções são mapeadas no espaço do cérebro, elas também entram nos sistemas de base cerebral. O sistema primário que lida com o corpo é, claramente, a instituição biomédica. No momento em que estas noções estão ligadas ao cérebro, o que previamente eram funções mentais tornam-se condições biomédicas. Isto é, portanto, outra forma significativa pela qual estes mapas são produtivos: neurociência e psicologia podem ligar seu trabalho ao empreendimento médico, incluindo a genética e a farmacologia. Ao trabalhar com mapas do cérebro, um território comum (literalmente) é criado onde essas várias disciplinas podem trabalhar.

Esta ligação torna claro dois pontos relacionados. Primeiro, ela ilumina porque o mapeamento cerebral tornou-se conectado a detecção de doenças. Livros como de Rita Carter, Mapping the Mind (1998), mostram 
quão ponderosa a metáfora do mapeamento está se tornando. A recente edição em brochura deste livro, embora em um formato reduzido, ainda conserva muitas das suas atrativas ilustrações e imagens dramáticas de cérebros ativos. Página após página apresenta pares justapostos de cérebros coloridos. A sensível distinção entre esses cérebros produz o forte argumento visual de que há uma diferença a ser percebida entre cérebros assassinos e pacíficos, padrões de pensamentos masculinos e femininos, ou estados conscientes e inconscientes da mente (Dumit, 2004). Uma vez que as condições são identificadas no cérebro, a lógica clínica diz que nós devemos ser hábeis para distinguir casos patológicos dos normais. Até o momento, normalidade em psicologia (especialmente em psicologia social e cognitiva) tem sido tradicionalmente concebida em termos muito diferentes do que na ciência clínica. Estas diferenças explicam alguns dos desconfortos expressos por psicólogos sobre as extrapolações feitas nas bases de seus trabalhos (por exemplo, sobre a possibilidade de 'testagem' para dislexia ou 'falsas memórias').

Enquanto que psicólogos falam sobre 'o cérebro', uma noção sustentada pela tendência de fazer estudos de grupo em mapeamento cerebral e de mensurar scans de diversos sujeitos retomando diferenças individuais está se tornando um alvo de importante crescimento, já que o mapeamento cerebral e os esforços biomédicos tornaram-se aliados. A possibilidade de reunir dados significativos sobre indivíduos pode assim parcialmente explicar o sucesso dos estudos de fMRI em contraste com o PET, que requer o cálculo de uma média. Mapas cerebrais, portanto, rearticulam a tensão entre a busca por universais da neurociência cognitiva e atenção investida para variações individuais nos estudos em genética (Plomin \& Kosslyn, 2001) ou ciência clínica. Este significativo desafio para noções tradicionais de 'normalidade' é especialmente nítido quando os mapas cerebrais são constituídos através de base de dados de scans e atlas eletrônicos (Beaulieu, 2001).

Em segundo lugar, este modo de relatar experimentos alinham a tecnologia do escaneamento cerebral com outros scanners biomédicos, como o raio-x, a ferramenta diagnóstica padrão. Pesquisadores que trabalham no mapeamento cerebral comumente relatam que eles são questionados se podem estender seus trabalhos para 
proporcionar testes diagnósticos para detectar as condições que eles estão investigando. Uma vez que temos o mapa, devemos estar aptos para usá-lo para navegação!

Também é importante notar que enquanto as noções anatômicas têm sustentado estes estudos aproximadamente na primeira década desta nova corrente, as áreas nas quais cérebro e comportamento estão sendo conectados são desenvolvidas em duas direções. Cérebros e comportamento estão sendo ligados no nível molecular, com inclinações genéticas (como no estudo de gêmeos descrito acima) ou possíveis implicações farmacológicas (como nos estudos que consideram neurotransmissores como fatores cruciais) (Cummings, 2000; Jetty, Charney, \& Goddard, 2001). Uma segunda tendência significativa é a de favorecer a matematização e a modelação como forma de traduzir processos cognitivos e noções neurocientíficas para uma linguagem comum (veja McIntosh, Fitzpatrick, \& Friston, 2001).

\section{O Corpo Político}

Mapas, não obstante, são também material de política. $\mathrm{O}$ mapeamento preciso do litoral foi um potencial ato de deslealdade não muitos séculos atrás. De fato, mapas são ainda potentes objetos envolvidos em sistemas de poder, e os mapas do cérebro não são diferentes. Mapeamento cerebral é, portanto, também produtor de novas demandas aos pesquisadores. Como a psicologia e a neurociência enfrentam áreas simbólicas significativas, como consciência, (falsa) memória, subjetividade e as bases neurais das relações sociais, eles devem esperar por níveis relacionados de preocupação social. Semelhantemente, como a neurociência cognitiva aumenta o uso do mapeamento para retratar seus resultados em termos de cérebro humano, ela adentra o domínio biomédico. Consequentemente, ela deixa de ser uma disciplina acadêmica relativamente isolada; o incremento da visibilidade leva a um grande suporte público, mas também a um grande escrutínio público. As intervenções de Fodor e Wolfe discutidas anteriormente são assim dignas de nota, porque suas avaliações da metodologia de mapeamento cerebral foram publicadas em mídia impressa proeminentes. Junto ao crescimento recente da 'relevância' da neurociência cognitiva vem o aumento da responsabilidade. Assim 
como a comunidade de geneticistas e o seu projeto para mapear genes, a neurociência enfrenta uma iniciativa Pan-Européia para examinar seus aspectos éticos, legais e sociais (ELSA). Um simpósio financiado pela WennerGren e a European Science Foundations foi organizado em Estocolmo, em setembro de 2001, e objetivava a reflexão sobre as questões levantadas por estes desenvolvimentos recentes na neurociência. Um pedido Americano para desenvolver a 'neuroética' também foi feito.2 A nova corrente da neurociência cognitiva social visa relacionar mecanismos cerebrais com referências tradicionais da psicologia social e está, portanto, tratando com questões sociais claramente significativas (veja Cacioppo et al., 2002).

Mapas cerebrais e especialmente as metodologias de fMRI estão no coração deste tipo de pesquisa. Novas iniciativas de financiamento têm lançado em meio a declarações e ratificações defensivas que 'a neurociência cognitiva social é uma grande ciência e está na vanguarda... Isto talvez assuste alguns que podem temer que ela nos leve estrada abaixo para o reducionismo biológico' (Azar, 2002). Diante dos pontos discutidos acima, uma abordagem reflexiva do contexto e conteúdo desta pesquisa pode ser mais efetiva debatendo-se a aceitabilidade deste empreendimento e leva para um debate frutífero, para além de acusações e recusas de um reducionismo biológico.

Este tipo de abordagem reflexiva nos leva a dois importantes tipos de considerações. Primeiro, em termos de conteúdo, ela nos conduz ao reconhecimento de que os objetos da psicologia e neurociência estão mudando, não simplesmente, diretamente, aprimorando. Isto também implica uma posição modesta no que diz respeito às possibilidades do mapeamento cerebral - uma posição que permite pesquisadores considerar o que está excluído pelos paradigmas dominantes em experimentos de mapeamento e como a metodologia pode ser enriquecida (Jack \& Roepstorff, 2002; Roepstorff 2002).

Segundo, em relação ao contexto deste trabalho, há algumas indicações de que pesquisadores estão tomando nota da importância social de suas atividades (Phelps, 2001). É preciso mais do que conversa fiada, uma vez que os pesquisadores entendem onde $\mathrm{e}$ como suas pesquisas são social e culturalmente localizadas, podem ser 
mais capazes para delinear suas responsabilidades como produtores de conhecimento e suas responsabilidades sociais. Isto oferece uma terceira alternativa para o problema da responsabilidade social dos pesquisadores - aqueles que parecem mais práticos e éticos ao negarem qualquer responsabilidade pelo o que acontece em suas próprias pesquisas, ou então assumirem todas as possíveis repercussões de seus trabalhos. É claro que isto não deveria ser considerado como de exclusiva responsabilidade dos pesquisadores. Instituições e agências de fomento talvez também precisam sustentar este aumento de consciência, pela estimulação da comunicação em curso (ao invés da post-hoc) entre pesquisadores de mapeamento cerebral e antropólogos, sociólogos e eticistas que são experts nestas questões.

Mapas são de fato produtivos: eles conectam o estudo da cognição com a vida diária, psicologia com $\mathrm{o}$ corpo e pesquisa científica com instituições de cuidado. Estas novas relações e as oportunidades que elas criam pode constituir o verdadeiro impacto do mapeamento e estes são, indiscutivelmente, de significado muito maior do que as objeções teóricas do reducionismo.

\section{Notas}

1. Veja o texto principal e respostas críticas em Posner e Raichle (1995).

2. A Dana Foundation, Universidade de Stanford e Universidade da Califórnia, em São Francisco, organizaram a conferência intitulada 'Neuroética: Mapeando o campo'. Veja o website da conferência e conferencista, http://scbe.stanford.edu/neuroethics_con ference.html.

\section{Referências}

Azar, B. (2002). At the frontier of science. Monitor on Psychology, $33(1)$ January: http://www.apa.org/monitor/fronti er.html (consulted 8 January 2002).

Beaulieu, A. (2001). Voxels in the brain: Neuroscience, informatics and changing notions of objectivity. Social Studies of Science, 31(5), 635-680.

Beaulieu, A. (2002). Images are not the (only) truth: Brain mapping, visual knowledge, and iconoclasm. Science Technology \& Human Values, 27(1), 53-86.

Begley, S. (1997, Spring/Summer). How to build a baby's brain. 
Newsweek (Special Edition), 2831.

Cacioppo, J.T., Berntson, G.G., Adolphs, R., Carter, C.S., Davidson, R.J., McClintock, M.K., McEwen, B.S., Meaney, M.J., Schacter, D.L., Sternberg, E.M.,nSuomi, S.S., \& Taylor, S.E. (2002). Foundations in social neuroscience. Cambridge, MA: MIT Press.

Carter, R. (1998). Mapping the mind. London: Weidenfeld \& Nicolson. Cummings, J.L. (2000). Cognitive and behavioral heterogeneity in Alzheimer's disease: Seeking the neurobiological basis. Neurobiology of Aging, 21(6), 845-861.

Dumit, J. (2004). Picturing personhood: Brain scans and biomedical identity. Princeton, NJ: Princeton University Press.

Fodor, J. (1999, 30 September). Diary. London Review of Books, 21(19): available on-line at http://www.lrb.co.uk/v21/n19/fod o01_.html

Jack, A.I., \& Roepstorff, A. (2002). Introspection and cognitive brain mapping: From stimulus-response to script-report. Trends in
Cognitive Sciences, 6(8), 333339.

Jetty, P.V., Charney, D.S., \& Goddard, A.W. (2001). Neurobiology of generalized anxiety disorder. Psychiatry Clinics of North America, 24(1), 75-100.

McIntosh, A., Fitzpatrick, S., \& Friston, K. (2001, 1 December). On the marriage of cognition and neuroscience. Neuroimage, 14(6), 1231-1237.

Phelps, E.A. (2001). Faces and races in the brain. Nature Neuroscience, 4(8), 775-776.

Phelps, E.A., O'Connor, K., Cunningham, W., Funayama, E.S., Gatenby, C., Gore, J., \& Banaji, M.R. (2000). Performance on indirect measure of race evaluation predicts amygdala activation. Journal of Cognitive Neuroscience, 12, 729-738.

Plomin, R., \& Kosslyn, S. (2001). Genes, brain and cognition. Nature Neuroscience, 4(12), 1153-1155.

Posner, M.I., \& Raichle, M.E. (1995). Pr'ecis of Images of mind. Behavioral and Brain Sciences, 18(2), 327-383.

Posner, M.I., \& Raichle M. (1997). Images of mind (2nd ed.). New 
York: Scientific American

Library.

Roepstorff, A. (2002). Transforming subjects into objectivity: An 'ethnography of knowledge' in a brain imaging laboratory. FOLK, Journal of the Danish Ethnographic Society, 44, 145170.

Thompson, P., Cannon, T., Narr, K.L., van Erp, T., Poutanen, V.-P., Huttunen, M., Lonnqvist, J., Standertskjold-Nordenstam, C.G., Kaprio, J., Khaledy, M., Dail, R., Zoumalan, C.I., \& Toga, A.W. (2001). Genetic influences on brain structure. Nature Neuroscience, 4(12), 1253-1258.

Wolfe, T. (1997, 2 February). Sorry, but your soul just died. The Independent on Sunday, Sunday Review, pp. 6-10.

Agradecimentos. A autora deseja agradecer Stuart Blume, Trudy Dehue, Brad Jorgensen, Sarah Riley, David Gooding, Helen Haste and Andreas Roepstorff, bem como o Editor deste periódico, pelos prestativos comentários e a discussão estimulante neste tópico.

Anne Beaulieu é pesquisadora senior na Networked Research and Digital Information (Royal Netherlands
Academy of Arts and Sciences) e professora visitante da Science Studies Centre, University of Bath, UK, onde ministrou a disciplina em Science, Culture and Communication (Department of Psychology). Ela tem estudado a comunidade do imageamento funcional desde meados de 1990. Seu trabalho atual direciona-se as questões sociológicas e culturais em bases de dados e compartilhamento de informação digital.

Endereço: Networked Research and Digital Information, NIWI-KNAW, Joan Muyskenweg 25, PO Box 95110, 1090 HC Amsterdam, The Netherlands. [email: anne.beaulieu@niwi.knaw.nl; website: http://www.niwi.knaw.nl/nerdi

Tradução: Marcos Adegas de Azambuja - Possui graduação em Psicologia pela Pontifícia Universidade Católica do Rio Grande do Sul (2003), mestrado em Psicologia pela Pontifícia Universidade Católica do Rio Grande do Sul (2006) e doutorado em Psicologia pela Pontifícia Universidade Católica do Rio Grande do Sul (2012), com período de doutorado sanduíche na London School of Economics (LSE). Atualmente é professor adjunto do Centro Universitário Franciscano. Tem experiência na área de Psicologia, com 
ênfase em Psicologia Social, atuando principalmente nos seguintes temas:

produção da subjetividade, psicologia, neurociências, saúde mental, educação e corpo.

E-mail: m_adegas@yahoo.com.br 